\title{
Dimensões de qualidade dos CFCs sob a percepção dos condutores de primeira habilitação
}

\author{
Genilson Lima e Silva ${ }^{1}$; Nildo Ferreira Cassundé Júnior ${ }^{2}$; Susanne Pinheiro Costa ${ }^{3}$
}

\begin{abstract}
Resumo: O estado pernambucano tem apresentando taxas de crescimento significativamente elevadas $(77,05 \%$ na última década) quanto a sua população de condutores. Neste cenário, os Centros de Formação de Condutores (CFCs) respondem pela qualidade na formação destes condutores, exercendo papel fundamental no tocante aos treinos e capacitação com vista a habilitar o cidadão para atuar como condutor. De natureza quantitativa, via escala do tipo Servqual, com 288 respondentes em uma CIRETRAN/PE, este estudo objetivou, a partir do ponto de vista do condutor da primeira habilitação, investigar por meio de dimensões a qualidade dos CFCs no interior do estado. Os dados foram analisados com o auxílio do SPSS. Os resultados apontam que alguns itens como instalações físicas, equipamentos modernos e disponibilidade dos instrutores como auxilio às dúvidas estão associados a qualidade. Em linhas gerais, os achados revelam que a qualidade dos CFCs é considerada muito boa.
\end{abstract}

Palavras-chave: Primeira habilitação; Centro de Formação de Condutores; Qualidade; Trânsito; Estudo quantitativo

\section{Quality dimensions of DTCs in the perception of driver's first license}

\begin{abstract}
The Pernambuco state has had significantly higher growth rates (77.05\% in the last decade) and its population of drivers. In this scenario,the Driver Training Centres (DTCs) are responsible for the quality of training of these drivers, playing a key role with respect to training and capacity building in order to enable the citizen to act as a conductor. Quantitative, via scale Servqual type, with 288 respondents in aCIRETRAN / PE, this study aimed, from the first qualification driver's point of view, investigate through dimensions the quality of DTCs in the state. Data were analyzed with SPSS.The results show that some items such as physical facilities, modern equipment and availability of instructors as an aid to the doubts are associated with quality. In general, the findings show that the quality of CFCs is considered very good.
\end{abstract}

Keywords: First qualification; Driver Training Centre; Quality; Traffic; quantitative study

\footnotetext{
${ }^{1}$ Curso de Adminitração. Universidade Federal do Vale do São Francisco - UNIVASF, Brasil. E-mail: genilsonls@ gmail.com

${ }^{2}$ Professor Adjunto I e membro do Colegiado de Enga de Produção da Univasf. Doutor em Administração (PROPAD/UFPE 2015); Mestre em Economia com ênfase em Comércio Exterior e Relações Internacionais (PIMES/UFPE 2006); MBA em Finanças Corporativas (MBADA/UFPE 2004) e Eng ${ }^{\circ}$ Civil (POLI/UPE, 2001). Parecerista de eventos e periódicos. Professor responsável pelas áreas de agronegócio e gestão econômico-financeira, membro permanente tanto da Especialização quanto do Mestrado em Gestão Pública da Univasf. Fundador do Observatório do Agronegócio. Pesquisador com ênfase em indicadores socioeconômicos e na análise das dinâmicas do agronegócio exportador do Vale das Frutas. Quando profissional de mercado, atuou como consultor financeiro com foco em análise de investimentos enquanto atuava como professor pelo DECON/UFPE. E-mail: nildo.cassunde@univasf.edu.br

${ }^{3}$ Doutora pelo Programa de Pós Graduação em Psicologia da Universidade Federal do Espírito Santo - UFES. Possui Mestrado em Enfermagem - Atenção à Saúde pela Universidade Federal do Rio Grande do Norte (UFRN) e graduação em Enfermagem pela Universidade Estadual da Paraíba (UEPB). Docente efetiva do Mestrado em Psicologia UNIVASF - disciplina Metodologia da Pesquisa em Psicologia. Docente da Especialização Gestão em Saúde UNIVASF - Módulos Planejamento Estratégico em Saúde / Organização e Funcionamento do SUS. Docente das Residências em Saúde da Família, Mental e Intensivismo - Módulo Educação em Saúde e Ensino em Serviço. Atualmente é Professora Adjunto III do Colegiado de Enfermagem da Universidade Federal do Vale do São Francisco - UNIVASF. Tem experiência na área de Saúde Coletiva / Saúde Pública / Saúde da Família, atuando principalmente nos seguintes temas: Enfermagem, Representações Sociais, Saúde Coletiva, Psicologia Social. E-mail:susanne.costa@univasf.edu.br
} 
Id on Line Revista Multidisciplinar e de Psicoloqia

Id on Line Revista Multidisciplinar e de Psicologia

\section{Semáforo da Introdução}

Em todo o mundo, os acidentes de trânsito representam a primeira causa de mortes na faixa etária entre 15 e 29 anos de idade, a segunda na faixa de 5-14 anos e terceira para aqueles entre 30 e 44 anos. A Organização Mundial de Saúde (OMS) estima que, na atualidade, 90\% dessas mortes acontecem em países em desenvolvimento e que, em conjunto, possuem menos da metade dos veículos do planeta. Atrelado a isto, as previsões desta organização indicam que a situação se agravará muito mais nestes países em função do aumento nos índices de motorização (WAISELFISZ, 2012).

Estudos organizados pela OMS que evidenciaram o aumento no número de acidentes de trânsito e levaram a Organização das Nações Unidas (ONU) a publicar o Global Plan for the Decade of Action for Road Safety 2011-2020, através da Resolução A/64/L44, que objetiva à redução de acidentes de trânsito no mundo, tendo dentre as suas metas o estabelecimento de planos diretores nacionais de redução destes. Uma política mundial foi desenvolvida entre as instituições World Health Organization, World Bank e Road Safety com vista a divulgar a prevenção mundial contra lesões nas estradas (WHO, 2004). Para conseguir tal feito, o Brasil estabeleceu o Pacto Nacional pela Redução de Acidentes no Trânsito dentro do Pacto pela Vida (DENATRAN, 2012). Este plano baseia-se em cinco áreas de atuação, que são: Fiscalização, Educação, Saúde, Infraestrutura e Segurança Veicular. O que torna a atribuição da gestão pública nesta esfera de relevância ímpar tendo em vista que se trata de um setor que tanto envolver aqueles que estão contidos neste universo como os que estão fora, já que envolve pedestres e a demais transeuntes.

No tocante às cinco áreas, cada uma destas tem objetivos e ações específicas, que devem ser seguidas por todas as políticas públicas implantadas na área de trânsito e transporte no Brasil (DENATRAN, 2011).

A área de educação apresenta onze ações e tem entre elas um ponto que merece destaque: a definição de indicadores que favoreçam a implementação de atividades e atendam as reais necessidades de segurança da população no trânsito. De acordo com Pinheiro, Pilleggi e Gaubeur (2006), analisando os fatores que concorrem para os acidentes de trânsito, têm-se como possíveis ações para a sua redução: a regulamentação específica; as intervenções no meio físico, no âmbito da engenharia de tráfego e transportes; o desenvolvimento tecnológico dos veículos e as ações educativas.

A formulação de indicadores quantitativos e/ou qualitativos acerca da qualidade dos serviços na área de trânsito pode facilitar a escolha de serviços que apresentam melhor qualidade, tais como os oferecidos pelos Centros de Formação de Condutores - CFCs que são responsáveis pela educação para o trânsito dos futuros condutores, pois a formação que oferecem relaciona-se diretamente à qualidade de dirigibilidade dos futuros condutores. 
Id on Line Revista Multidisciplinar e de Psicoloqia

Id on Line Revista Multidisciplinar e de Psicologia

O período educativo oferecido pelos CFCs é divido em duas etapas: teórica e prática. O curso teórico é composto de 45 horas e contém os assuntos de legislação, direção defensiva, primeiros socorros, mecânica básica e meio ambiente e cidadania. Após a conclusão do curso, o candidato a condutor realizará uma prova teórica no DETRAN sobre o conteúdo e, se aprovado, irá para a segunda parte, que é o curso prático. Todo este processo obedece às resoluções 168 e 169 do Conselho Nacional de Trânsito (DENATRAN, 2004).

O curso prático é composto por 20 horas-aula para a "categoria moto" ou Categoria A e 25 horas para a "categoria carro" ou Categoria B. O candidato a condutor pode escolher entre três tipos de categorias: A, B ou, ainda, $\mathrm{AB}$, de acordo com as resoluções supracitadas. Após o curso prático, o candidato realizará prova prática pela qual demonstrará habilidades adquiridas no $\mathrm{CFC}$ e, se aprovado, será um novo condutor.

De acordo com o DENANTRAN, o número de pessoas habilitadas no Brasil era de 60.498.277 de condutores em 2015, numa população de 204.450.649 de habitantes, o que representa uma taxa de pessoas habilitadas de $29,59 \%$ da população. Segundo o DETRAN de Pernambuco, os condutores do estado eram em número de 2.080.118 até março de 2016, numa população de 9.397.069 de pessoas (IBGE, 2016). Logo, 22,12\% da população geral do estado estão habilitados a conduzir veículos motorizados. Neste tocante, a população de condutores no estado de Pernambuco vem apresentando taxas de crescimento elevadas, sendo que nos últimos dez anos acrescentou um total de 922.526 novos condutores, o que representa um crescimento de $77,05 \%$ nesta população, que quase dobrou na última década.

Para a OMS, 90\% dos acidentes de trânsito são causados por erro humano (OPAS, 2013), porém, ainda não é possível estabelecer uma relação de causalidade entre aqueles ocasionados por falha humana com possível deficiência na formação de condutores. Assim, a implementação de melhorias na qualidade dos CFCs terá como consequência imediata a melhor preparação na formação dos futuros motoristas e, com isso, redução nos números de acidentes ocasionados por falha humana (SILVA, 2005). Diante desses fatores, este trabalho busca responder a seguinte inquietação: Sob a percepção dos futuros condutores, qual a qualidade dos cursos oferecidos nos Centros de Formação de Condutores - CFC sob responsabilidade da CIRETRAN/PE em Petrolina? Para tanto, o objetivo tratou de investigar por meio de dimensões, a partir do ponto de vista do condutor da primeira habilitação antes da realização do exame prático, a qualidade nos Centros de Formação de Condutores no interior do estado pernambucano, mais especialmente em Petrolina.

A contar dos estudos como Santos (2002), Abreu, Alves e Lima (2006), Vieira (2008), Raad et al (2008), Sobrinho (2010), Cristo e Anchieri (2010), Machio (2011), Nakano, Sampaio, Silva (2011), Bissoli, Mazetto e Carlos (2012); Stefano e Casarotto Filho (2013), Silva e Trenhago (2014), Sartori, Larocca e Almqvist (2014); Rodrigues e Jayo (2016) percebeu-se as pesquisas não tem concentrado esforços sobre o macrocampo trânsito, habilitação e qualidade dos Centros de Formação de 
Id on Line Revista Multidisciplinar e de Psicologia

Id on Line Revista Multidisciplinar e de Psicologia

Condutores. Na base Spell (2016), por exemplo, não há nenhum trabalho tratando dos Centros de Formação de Condutores. Dos achados, identificou-se que quando os valiosos achados tratam da primeira habilitação (MACHIO, 2011; NAKANO; SAMPAIO, 2011) não tratam dos aspectos referentes a qualidade dos CFCs; e quando tratam da qualidade dos CFCs (STEFANO; CASAROTTO FILHO, 2013), não observam sob o ponto de vista da primeira habilitação. Nuance relevante tendo em vista que a primeira habilitação exige percepções acuradas de práticas que nunca antes haviam sido percebidas antes do estudo para se obter a carteira nacional de habilitação - CNH (NAKANO; SAMPAIO; SILVA, 2011).

Neste sentido, espera-se que os achados contribuam não apenas para ampliar o escopo de achados científicos sobre o tema, mas, também para a formulação de ações e estratégias que proporcionem a avaliação contínua da qualidade das empresas que atuam para a formação de condutores, melhorando a qualidade dos serviços prestados e, indiretamente, do trânsito da região na qual o estudo se fez.

\section{Semáforo: O trânsito e os CFCs: relevâncias}

Segundo dados, o Brasil em meados da década de noventa (1993-1997) registrou fortes aumentos no número de mortes relacionadas ao trânsito (WAISELFISZ, 2012). E a partir do novo Código de Trânsito, que vigora desde 1998, proporcionou nos seus primeiros anos queda nos números devido ao rigor do novo código e as campanhas que este originou. Contraditoriamente, a partir do ano 2000, é possível observar novos acréscimos da ordem de 4,8\% ao ano no número de acidentes de óbitos causados por acidentes de trânsito, fazendo com que os quantitativos retornassem, já em 2005, ao patamar de 1997, para continuar crescendo de forma contínua e sistemática. Com os aumentos no número de mortes no trânsito, segundo previsões, espera-se que eles tenham superado o de homicídios já a partir de 2015 (WAISELFISZ, 2012).

No estado de Pernambuco, esse mesmo fenômeno no tocante ao aumento no número de acidentes acompanha a realidade nacional. Enquanto no Brasil o crescimento nos últimos anos registrou patamares na ordem de 41,4\%, no estado pernambucano, a taxa de crescimento foi de 33,9\% sendo bem menor do que a média Nordeste que apresentou uma taxa de crescimento de 74,4\% (WAISELFISZ, 2012).

Estudos apontam como principais eventos causadores dos acidentes de trânsito o excesso de velocidade; desrespeito à legislação do trânsito e sinalização; consumo de álcool ao volante e características como idade e gênero, além da imaturidade associada ao consumo de bebidas alcoólicas e ao excesso de velocidade (PEREIRA, NEVES, 2013); assim como o aumento indisciplinado do segmento de condutor de veículo motorizado de duas ou três rodas, com ou sem carro lateral (VIAS 
Id on Line Revista Multidisciplinar e de Psicoloqia

Id on Line Revista Multidisciplinar e de Psicologia

SEGURAS, 2016), a exemplo das motocicletas, motonetas e ciclomotores em geral (CONTRAN, 2016).

Dessa forma, a complexidade cada vez maior da realidade da segurança no trânsito no Brasil impõe uma ação coordenada de governo nas três esferas, atuando de forma articulada com a sociedade civil para o enfrentamento do problema (MOYSÉS, 2012).

\section{Os Centros de Formação de Condutores e educação para o trânsito}

O CFC - Centro de Formação de Condutores é responsável pela formação de condutores e de candidatos para obtenção da Carteira Nacional de Habilitação (CNH). Assim, essas empresas exercem um papel fundamental na sociedade, pois são elas que treinam, capacitam e habilitam o cidadão para atuar como condutor.

Com o trânsito apresentando níveis de violência cada dia mais elevados, essas organizações devem desenvolver suas habilidades organizacionais não só para atrair clientes, mas sim ampliar e promover o desenvolvimento social desses novos condutores, incutindo valores sociais como respeito às leis e regras, autoconhecimento, prudência, disciplina, entre outros.

As três esferas, União, Estados e Municípios atuam em conjunto com o objetivo de desenvolver esses valores através da educação, fiscalização e segurança no trânsito, criando assim uma padronização dos critérios técnicos, sendo a responsabilidade máxima do CONTRAN - Conselho Nacional de Trânsito, que rege de forma harmônica os órgãos estaduais (DETRAN's) e departamentos municipais de trânsito, quando houver este.

Art. $5^{\circ} \mathrm{O}$ Sistema Nacional de Trânsito é o conjunto de órgãos e entidades da União, dos Estados, do Distrito Federal e dos Municípios que tem por finalidade o exercício das atividades de planejamento, administração, normatização, pesquisa, registro e licenciamento de veículos, formação, habilitação e reciclagem de condutores, educação, engenharia, operação do sistema viário, policiamento, fiscalização, julgamento de infrações e de recursos e aplicação de penalidades (DENATRAN, 1997).

A Resolução do Conselho Nacional de Trânsito (Contran) no 358, de 13 de agosto de 2010, regulamenta o credenciamento de instituições ou entidades públicas ou privadas para o processo de capacitação, qualificação e atualização de profissionais, e de formação, qualificação, atualização e reciclagem de candidatos e condutores (DENATRAN, 2010), como determina o Art. $7^{\circ}$ :

Art. $7^{\circ}$ As auto-escolas a que se refere o art. 156 do CTB, denominadas Centros de Formação de Condutores - CFC são empresas particulares ou sociedades civis, constituídas sob qualquer das formas previstas na legislação vigente 
$\S 1^{\circ}$ Os CFC devem ter como atividade exclusiva o ensino teórico e/ou prático visando à formação, atualização e reciclagem de candidatos e condutores de veículos automotores;

$\S 2^{\circ}$ Os CFC serão credenciados pelo órgão ou entidade executivo de trânsito do Estado ou do Distrito Federal por período determinado, podendo ser renovado por igual período, desde que atendidas as disposições desta Resolução.

$\S 3^{\circ}$ Para efeito de credenciamento pelo órgão de trânsito competente, os CFC terão a seguinte classificação:

I - "A" - ensino teórico técnico;

II - "B" - ensino prático de direção; e

III - "AB" - ensino teórico técnico e de prática de direção.

$\S 4^{\circ}$ Cada CFC poderá se dedicar ao ensino teórico técnico ou ao ensino prático de direção veicular, ou ainda a ambos, desde que certificado e credenciado para tal.

$\S 5^{\circ} \mathrm{O}$ CFC só poderá preparar o aluno para o exame de direção veicular se dispuser de veículo automotor da categoria pretendida pelo candidato.

$\S 6^{\circ}$ As dependências físicas do CFC deverá ter uso exclusivo para o seu fím.

Dessa forma, estas organizações não apresentam liberdade de atuação, estando ligadas exclusivamente ao ensino dos novos condutores. Segundo Assmann, Moyano e Angnes (2013), por ser um serviço que o cliente não experimenta antes de adquirir, deve ser desenvolvido de forma a criar o valor necessário para conquistar e satisfazer clientes. Tais empresas, portanto, precisam admitir que o seu papel não acaba quando aprovam os candidatos em testes teóricos e práticos, pois, exercem papel fundamental de um transito seguro para toda a sociedade através da educação que oferecem.

Fica portanto de responsabilidade do órgão executivo estadual de trânsito de cada estado ou do distrito federal, respectivamente, a fiscalização dos CFCs para renovação do seu credenciamento, conforme estabelecido na resolução 358 do CONTRAN (2010). Cabe aos DETRAN's a verificação dos quesitos tangíveis como instalações físicas, equipamentos e material didático, além de ser cobrado um índice de aprovação superior a $60 \%$ nos exames teóricos e práticos.

\section{Qualidade de serviços}

O crescimento do setor de serviços, especialmente nos aspectos econômicos, trouxe também a busca pela melhoria da gestão dos CFCs. Deste modo, torna-se necessário interpretar as necessidades do consumidor e a avaliação do serviço prestado, o que reforça o nível de competitividade e estabelece relacionamento com o cliente, centrando-se as vantagens competitivas nas operações do prestador do serviço (STEFANO; CASAROTTO FILHO, 2013).

A qualidade do serviço refere-se ao grau em que um serviço atende ou supera as expectativas de sua clientela. Quanto melhor os clientes percebem a entrega efetiva do serviço, ficarão contentes; "se estiver abaixo das expectativas, ficarão insatisfeitos e julgarão a qualidade de acordo com seu grau de satisfação" para com o serviço (LOVELOCK, WRIGHT, 2004, p. 102). Sendo assim, a qualidade passou a ser indispensável para assegurar a sobrevivência das organizações de qualquer natureza e, em especial, no meio empresarial (ASSMANN, MOYANO, ANGNES, 2013). 
Id on Line Revista Multidisciplinar e de Psicologia

Id on Line Revista Multidisciplinar e de Psicologia

No que tange à qualidade de serviços prestados por CFC's, Stefano e Casarotto Filho (2013) evidenciam que existe uma latente necessidade de alterações, sendo a qualidade do serviço abaixo do esperado especialmente no quesito "atendimento", o que pode influenciar diretamente na vantagem competitiva da empresa.

Neste ambiente cada vez mais competitivo, as micro, pequenas ou grandes empresas, a fim de prosperarem e garantirem a sua sobrevivência, necessitam inovar constantemente na busca de qualidade e tecnologia, obtendo assim vantagens e diferenciais em relação aos concorrentes (TRINKS, BORBA, 2013).

No que diz respeito à qualidade, é de extrema importância que qualidade de vida, motivação e satisfação dos colaboradores, especialmente daqueles que trabalham com a educação para o trânsito, constituam o elemento básico das organizações (TRINKS, BORBA, 2013), influenciando também na melhoria da situação do trânsito brasileiro.

Com estudos sinalizando as falhas humanas como a principal causa de acidentes, Alves e Gomes (2014) afirmam que a educação para o trânsito serve como medida preventiva de acidentes, principalmente entre os condutores jovens, que apresentam comportamentos inadequados no trânsito. Deste modo, torna-se precioso avaliar como vem sendo desenvolvidos os trabalhos pelas CFCs, pois, estas devem preocupar-se com a qualidade do serviço prestado (em especial devido a concorrência), investindo em capacitações e reciclagens para o seu quadro de funcionários, contribuindo com a satisfação do cliente e aprimorando a responsabilidade social que lhes cabe.

\section{Procedimentos metodológicos}

Trata-se de estudo descritivo e exploratório, com abordagem quantitativa. O cenário foi a VIII Ciretran de Petrolina/PE, responsável pelo atendimento de demandas referentes à primeira habilitação, dentre outras, das cidades pernambucanas de Afrânio, Dormentes, Lagoa Grande, Petrolina e Santa Maria da Boa Vista.

Participaram futuros condutores que concluíram o processo de primeira habilitação, antes da realização da prova prática de direção veicular. Foram incluídos todos os candidatos a condutores, independente da idade, que aceitaram participar e estavam aptos a realizar o teste prático de direção, visto que tinham concluído o período educativo no CFC, respeitando a ética que envolve as pesquisas com seres humanos.

O tamanho amostral foi calculado através de fórmula de Amostragem para População Finita definida por Silva et al. (1997), com estimativas de proporção entre os exames de primeira habilitação e os exames de adição de categoria: 
Id on Line Revista Multidisciplinar e de Psicologia

Id on Line Revista Multidisciplinar e de Psicologia

$\mathbf{n =} \frac{Z^{2} \times P \times Q \times N}{e^{2} \times(N-1)+Z^{2} \times P \times Q}$

\begin{tabular}{|c|c|}
\hline Onde: & Valor \\
\hline$Z=$ Nível de Confiança & $95 \%$ \\
\hline $\mathrm{P}=$ Quantidade de Exames Primeira Habitação esperado (\%) & $90 \%$ \\
\hline $\mathrm{Q}=$ Quantidade de Exames Adição categoria esperado (\%) & $10 \%$ \\
\hline N = População Total & 863 \\
\hline e = Nível de Precisão $(\%)$ & $3 \%$ \\
\hline Tamanho da amostra $(n)=$ & 266 \\
\hline
\end{tabular}

O tamanho da população foi calculado pela média dos últimos dozes meses dos candidatos que realizaram exames práticos na CIRETRAN de Petrolina, tendo como referência os exames de primeira habilitação, ou seja, exames na categoria A para moto e/ou os exames da categoria B para carro. E sendo assim, em um universo de 863 potenciais condutores, para respeitar um nível de precisão de 3\% e um nível de segurança de 95\%, a amostra mínima calculada foi de 266.

A pesquisa foi realizada por meio de questionário estruturado contendo predominantemente questões fechadas, com base na escala Servqual. Este modelo teve sua primeira publicação no ano de 1988, passando por várias adaptações desde então com objetivo de se adequar a variabilidade dos serviços oferecidos (ZEITHAML, BITNER, 2003). Apesar de receber algumas críticas, foi e é bastante utilizado na verificação da qualidade no setor de serviços. Apresenta cinco dimensões: Tangibilidade, Confiabilidade, Sensibilidade, Segurança e Empatia. Em cada uma dessas dimensões encontram-se vários itens em escala e que totalizam 22 componentes (LOVELOCK; WRIGHT, 2004).

Para este estudo, realizou-se adaptação na escala Servqual, já que esta não apresenta nenhum item referente à acessibilidade ao serviço. No entanto, este quesito é tido como um parâmetro importante, já que a legislação refere à necessidade de adaptação das organizações aos portadores de necessidades especiais e, assim, merece ser avaliado.

O questionário foi aplicado nas dependências da Ciretran de Petrolina/PE antes da realização de prova prática de direção, tendo pelo cálculo amostral um número mínimo de 266 candidatos. No entanto, por acessibilidade ampliou-se a amostra para 288 respondentes; sendo este o número final de participantes incluídos na pesquisa.

Os dados foram tabulados e analisados através do programa Statistical Package for the Social Sciences - SPSS versão 20, sendo apresentados através de tabelas. 
Id on Line Revista Multidisciplinar e de Psicoloqia

Id on Line Revista Multidisciplinar e de Psicologia

\section{Análise dos Resultados}

A amostra, constituída por 288 pessoas, foi formada por $60,8 \%$ do sexo masculino, solteiros (70,6\%) e com idade variando entre 18 e 23 anos (51,4\%) e 24 a 29 anos (19,8\%). Sendo assim, de acordo com um nível de confiança estabelecido de 95\%, o perfil predominante do VII CIRETRAN/PE é de homens solteiros com idade variando de 18 a 23 anos. Grande parte $(68,8 \%)$ tem escolaridade igual ou superior ao ensino médio completo, com renda familiar de até 1 salário mínimo $(60,1 \%)$ e são clientes de 16 autoescolas da região. Ademais, como o universo deste estudo contemplou apenas candidatos de primeira habilitação, era esperado que, de fato, o perfil fosse composto por candidatos jovens.

A diagramação abaixo apresenta o perfil da amostra descrita acima.

Figura 1 - Diagramação da amostra dos condutores de primeira habilitação no VII CIRETRAN

Sexo

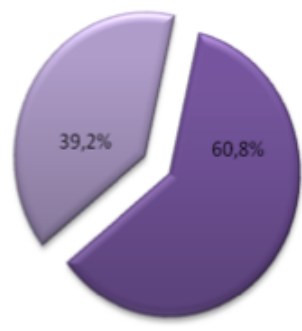

Masculino

areminino

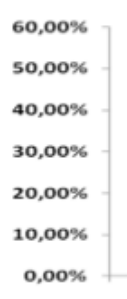

$0,00 \%$
Idade

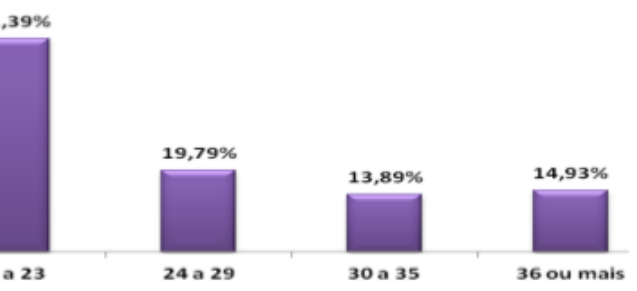

\section{Escolaridade}

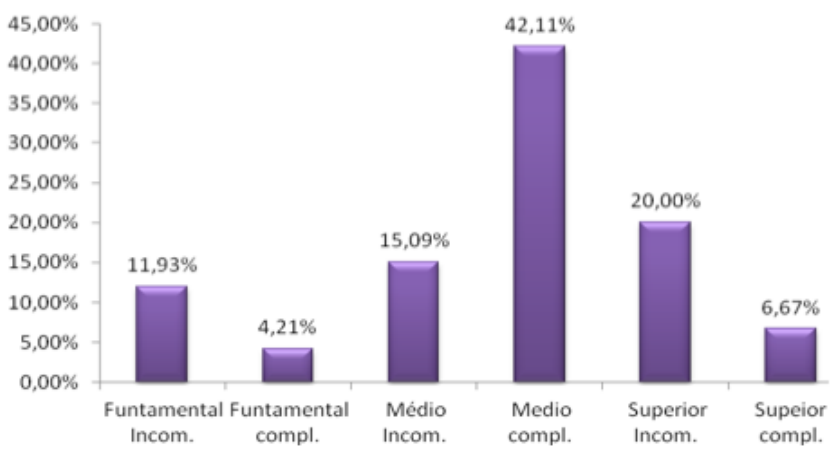

No relacionado ao perfil, Waiselfisz (2013) revela que o sexo masculino apresenta elevados índices entre as vítimas letais dos acidentes de trânsito, já que 82,3\% das mortes por este tipo de acidente em 2011 pertenciam ao sexo masculino. $\mathrm{O}$ autor ainda refere que o resultado referente à faixa etária revelou um perfil de jovens como as maiores vítimas nos acidentes de trânsito.

A seguir, apresenta-se, na companhia das tabelas, os resultados em separado no que se refere as cinco dimensões determinantes que definem qualidade e que estão divididas na tabela Servqual através de questionamentos; sendo nomeados em discriminado entre Tangibilidade, Confiabilidade, Sensibilidade, Segurança e Empatia, demonstradas nesta ordem. Oportuno destacar que os parâmetros 
Id on Line Revista Multidisciplinar e de Psicoloqia

Id on Line Revista Multidisciplinar e de Psicologia

apresentaram missing e sendo assim, cada um traz separadamente o número de pessoas (em cada quadrante sinalizado por N) que efetivamente responderam a questão. As respostas são graduadas em números que variam de 1 a 5 , conforme se apresenta.

\section{Tangibilidade}

Esta dimensão faz alusão às características físicas que envolvem a empresa, dentre eles equipamentos, inclusive os materiais utilizados no processo de ensino-aprendizagem, aparência dos funcionários e instalações físicas, conforme discriminado na Tabela 1 e ilustrado na Figura 2 a seguir.

TABELA 1: Resultados acerca da Tangibilidade. Para um N absoluto de 288 questionários.

Petrolina-PE, 2016.

\begin{tabular}{c|c|c|c|c|c|c|c}
\hline TANGIBILIDADE & $\mathbf{1}$ & $\mathbf{2}$ & $\mathbf{3}$ & $\mathbf{4}$ & $\mathbf{5}$ & $\begin{array}{c}\text { Media } \\
\text { Ponderada }\end{array}$ & $\begin{array}{c}\text { Desvio } \\
\text { Padrão }\end{array}$ \\
\hline $\begin{array}{c}\text { Equipamentos } \\
\text { Modernos (N=284) }\end{array}$ & $8,45 \%$ & $4,23 \%$ & $18,66 \%$ & $14,08 \%$ & $54,58 \%$ & $\mathbf{4 , 0 2}$ & 0,20 \\
\hline $\begin{array}{c}\text { Instalações Físicas } \\
\text { (N=284) }\end{array}$ & $6,34 \%$ & $1,76 \%$ & $12,32 \%$ & $16,55 \%$ & $63,03 \%$ & $\mathbf{4 , 2 8}$ & 0,25 \\
\hline $\begin{array}{c}\text { Acessibilidade } \\
\text { (N=281) }\end{array}$ & $3,20 \%$ & $1,78 \%$ & $4,27 \%$ & $10,68 \%$ & $80,07 \%$ & $\mathbf{4 , 6 3}$ & 0,34 \\
\hline $\begin{array}{c}\text { Material didático } \\
\text { Atualizado (N=284) }\end{array}$ & $2,11 \%$ & $1,06 \%$ & $3,52 \%$ & $7,39 \%$ & $85,92 \%$ & $\mathbf{4 , 7 4}$ & 0,37 \\
\hline $\begin{array}{c}\text { Aparência dos } \\
\text { Funcionários } \\
\text { (N=286) }\end{array}$ & $2,10 \%$ & $0,70 \%$ & $5,59 \%$ & $7,69 \%$ & $83,92 \%$ & $\mathbf{4 , 7 1}$ & 0,36 \\
\hline
\end{tabular}

Fonte: Dados da Pesquisa de campo

Figura 2 - Dimensão Tangibilidade em parâmetros

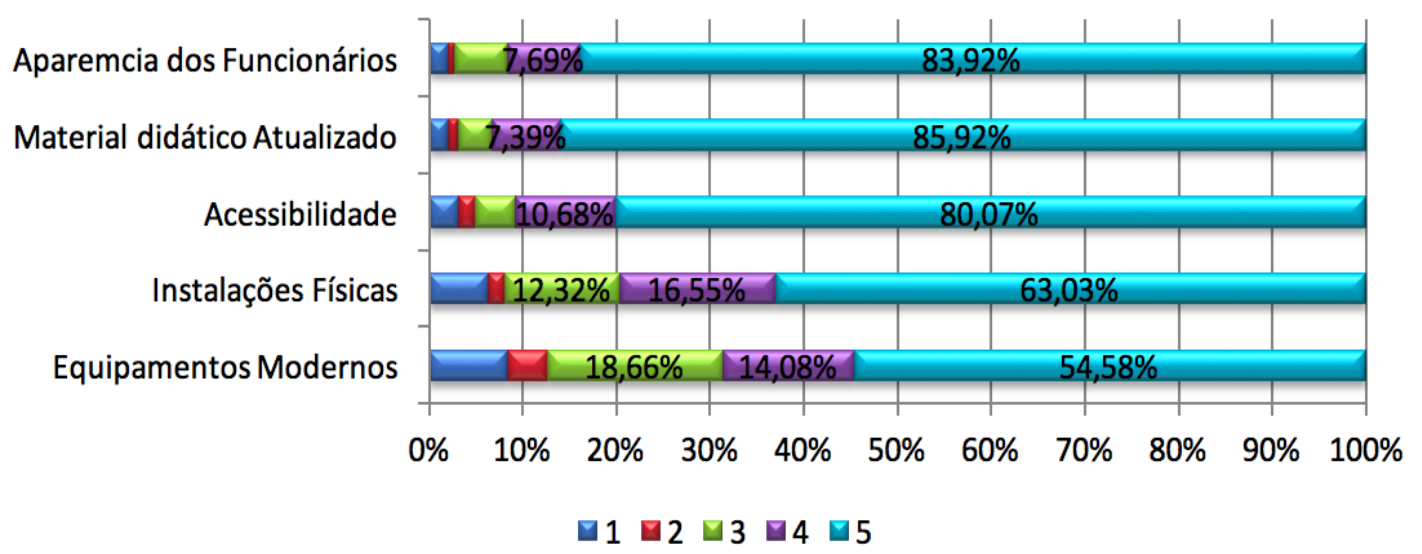

A primeira variável do determinante tangibilidade referiu-se a equipamentos modernos, questionando-se ao usuário a sua opinião acerca do CFC em que realizou o curso. Verificou-se que $68,66 \%$ atribuíram nota 4 ou 5 a este item, e 54,58\% atribuíram nota máxima, ou seja, a maioria dos 
Id on Line Revista Multidisciplinar e de Psicoloqia

Id on Line Revista Multidisciplinar e de Psicologia

usuários dos CFCs disseram que estas organizações apresentam equipamentos modernos. A média desse item foi de 4,02 numa escala até 5 pontos, porém, foi a menor média entre os itens referente à tangibilidade verificados na pesquisa.

As instalações físicas exibiram um desempenho elevado segundo os usuários dos CFCs, sendo que 79,58\% atribuíram nota 4 ou 5 a este item, com 63,03\% atribuindo nota máxima. Sendo assim, mais de $60 \%$ dos usuários gostaram das instalações do CFC onde realizaram o processo de primeira habilitação. Este aspecto apresentou uma média de 4,28 e, juntamente com o anterior, apresentam rendimento superior a $80 \%$.

A Acessibilidade tinha como objetivo verificar se o CFC apresenta facilidade de acesso às áreas de ensino e treinamento como estabelece a legislação. Neste componente, verificou-se que $89,79 \%$ dos usuários atribuíram nota 4 ou 5 e que 79,23\% apontaram a nota máxima, com média de 4,58 , apresentado um rendimento acima de $95 \%$.

No tocante ao Material didático utilizado pelo CFC no processo de ensino, este apresentou avaliação que tem média 4,74 , sendo que $93,31 \%$ atribuíram nota 4 ou 5 . Desse total, $85,92 \%$ impuseram nota máxima ao item. O rendimento desse quesito foi de mais de $95 \%$. Já a aparência dos funcionários representada por roupas, odores e cuidados pessoais teve desempenho médio de 4,71, com rendimento acima de $95 \%$. Do total de respondentes, 91,61\% atribuiu nota 4 ou 5, sendo que $83,92 \%$ indicaram nota máxima ao questionamento.

\section{Confiabilidade}

Esta dimensão traz ao participante a oportunidade de avaliar itens referentes à capacidade ou habilidade de realizar o serviço oferecido de modo confiável, dentre eles podemos citar a execução sem erros, interesse na solução de problemas que tenham surgido ao longo do processo, entre outros. Os resultados encontram-se discriminados na Tabela 2 e ilustrado na Figura 3 a seguir.

TABELA 2: Resultados acerca da Confiabilidade. Para um N absoluto de 288 questionários. PetrolinaPE, 2016.

\begin{tabular}{c|c|c|c|c|c|c|c}
\hline CONFIABILIDADE & $\mathbf{1}$ & $\mathbf{2}$ & $\mathbf{3}$ & $\mathbf{4}$ & $\mathbf{5}$ & $\begin{array}{c}\text { Média } \\
\text { Ponderada }\end{array}$ & $\begin{array}{c}\text { Desvio } \\
\text { Padrão }\end{array}$ \\
\hline $\begin{array}{c}\text { Promessa de } \\
\text { execução na data } \\
\text { estipulada (N=284) }\end{array}$ & $2,46 \%$ & $0,35 \%$ & $4,23 \%$ & $8,80 \%$ & $84,15 \%$ & $\mathbf{4 , 7 2}$ & 0,36 \\
\hline $\begin{array}{c}\text { Interesse na solução } \\
\text { dos problemas } \\
\text { (N=284) }\end{array}$ & $1,76 \%$ & $1,41 \%$ & $9,15 \%$ & $14,08 \%$ & $73,59 \%$ & $\mathbf{4 , 5 6}$ & 0,30 \\
\hline $\begin{array}{c}\text { Serviço certo desde } \\
\text { começo (N=287) }\end{array}$ & $1,74 \%$ & $1,39 \%$ & $5,92 \%$ & $7,67 \%$ & $83,28 \%$ & $\mathbf{4 , 6 9}$ & 0,35 \\
\hline
\end{tabular}


Id on Line Revista Multidisciplinar e de Psicologia

Id on Line Revista Multidisciplinar e de Psicologia

\begin{tabular}{c|c|c|c|c|c|c|c}
\hline $\begin{array}{c}\text { Comprometimento } \\
\text { na execução (N=287) }\end{array}$ & $1,05 \%$ & $1,05 \%$ & $5,92 \%$ & $6,27 \%$ & $85,71 \%$ & $\mathbf{4 , 7 5}$ & 0,37 \\
\hline $\begin{array}{c}\text { Execução sem erros } \\
(\mathbf{N}=\mathbf{2 8 6})\end{array}$ & $2,8 \%$ & $1,75 \%$ & $6,99 \%$ & $14,34 \%$ & $74,13 \%$ & $\mathbf{4 , 5 5}$ & 0,31 \\
\hline
\end{tabular}

Fonte: Dados da Pesquisa de campo

Figura 3 - Dimensão Confiabilidade em parâmetros

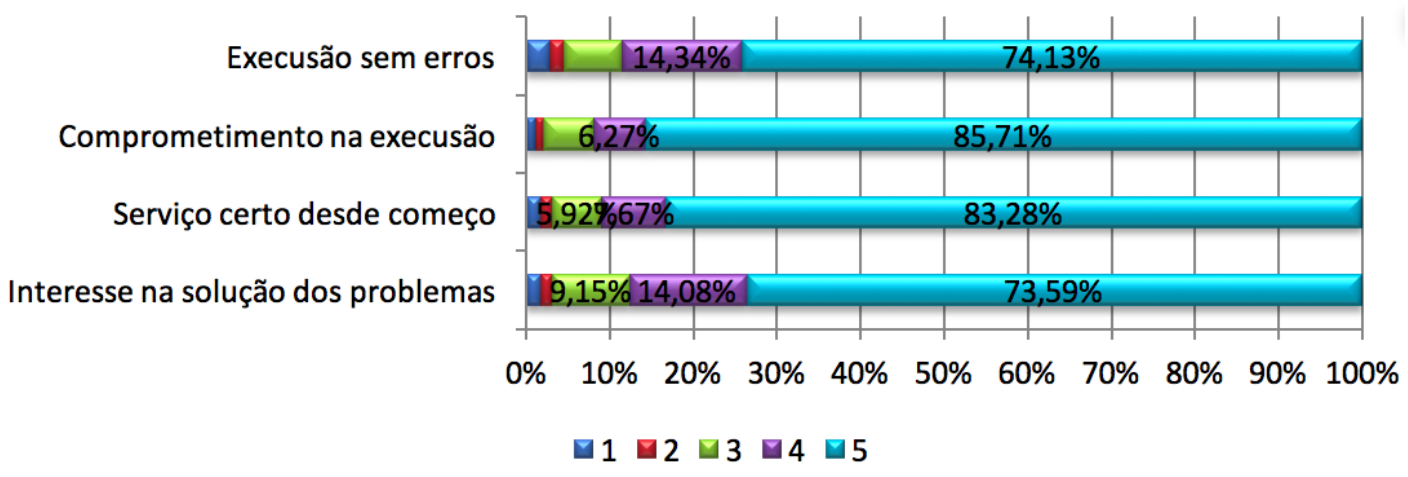

A promessa de execução dos cursos teóricos e práticos na data estipulada pelo CFC apresentou uma avaliação acentuada sendo que $92,95 \%$ atribuíram nota 4 ou 5 ao quesito, e desses, 84,15\% conferiram nota máxima ao CFC onde realizaram o processo de primeira habilitação. Assim, os clientes apresentaram um bom índice de satisfação nos prazos para conclusão dos cursos já que este item teve média de 4,72 .

No que se refere ao interesse na solução dos problemas apresentados, este manteve média alta $(4,56)$. Os clientes entendiam que o CFC apresentou interesse na solução de problemas que surgiram durante o processo de primeira habilitação, já que este quesito teve $87,67 \%$ dos clientes que aplicaram nota 4 ou 5 , sendo que $73,59 \%$ impuseram nota máxima.

Os usuários acreditam que o CFC realizou seu serviço de maneira correta desde o começo (média de 4,69), comprometido na execução dos serviços de primeira habilitação, com média de 4,75. 91,98\% dos clientes atribuíram nota 4 ou 5 neste item e 85,71\% impuseram nota máxima ao CFC. Dessa forma, os participantes avaliaram as autoescolas como tendo um rendimento acima dos 95\%, com o processo de aprendizagem feito corretamente.

Os usuários também pontuam que o CFC parecia executar sem erros as suas tarefas, com média de 4,55. Entretanto, o menor desempenho no aspecto confiabilidade, foi apontado para tal aspecto, embora 74,13\% dos respondentes tenham atribuído nota máxima à questão. 
Id on Line Revista Multidisciplinar e de Psicologia

Id on Line Revista Multidisciplinar e de Psicologia

\section{Sensibilidade}

A sensibilidade refere-se ao fornecimento do serviço de forma motivada, com atendimento rápido, pontual e disposto a ajudar. Sendo assim, os participantes julgaram itens acerca de presteza no atendimento e disponibilidade dos funcionários, conforme discriminados na Tabela 3 e ilustrado na Figura 4 a seguir.

TABELA 3: Resultados acerca da Sensibilidade. Para um N absoluto de 288 questionários. PetrolinaPE, 2016.

\begin{tabular}{c|c|c|c|c|c|c|c}
\hline SENSIBILIDADE & $\mathbf{1}$ & $\mathbf{2}$ & $\mathbf{3}$ & $\mathbf{4}$ & $\mathbf{5}$ & $\begin{array}{c}\text { Média } \\
\text { Ponderada }\end{array}$ & $\begin{array}{c}\text { Desvio } \\
\text { Padrão }\end{array}$ \\
\hline $\begin{array}{c}\text { Cumprir os prazos } \\
\text { de execução } \\
\text { (N=284) }\end{array}$ & $2,82 \%$ & $0,70 \%$ & $3,52 \%$ & $8,45 \%$ & $84,51 \%$ & $\mathbf{4 , 7 1}$ & 0,36 \\
\hline $\begin{array}{c}\text { Presteza no } \\
\text { atendimento } \\
\text { (N=285) }\end{array}$ & $1,4 \%$ & $1,75 \%$ & $6,67 \%$ & $10,53 \%$ & $79,65 \%$ & $\mathbf{4 , 6 5}$ & 0,34 \\
\hline $\begin{array}{c}\text { Disponibilidade } \\
\text { para ajudar o } \\
\text { aluno (N=285) }\end{array}$ & $2,11 \%$ & $0,70 \%$ & $6,67 \%$ & $10,88 \%$ & $79,65 \%$ & $\mathbf{4 , 6 5}$ & 0,34 \\
\hline $\begin{array}{c}\text { Nunca estavam } \\
\text { ocupados para } \\
\text { atender os alunos } \\
\text { (N=283) }\end{array}$ & $3,18 \%$ & $1,41 \%$ & $10,06 \%$ & $16,96 \%$ & $67,84 \%$ & $\mathbf{4 , 7 5}$ & 0,27 \\
\hline
\end{tabular}

Fonte: Dados da Pesquisa de campo

Figura 4 - Dimensão Sensibilidade em parâmetros

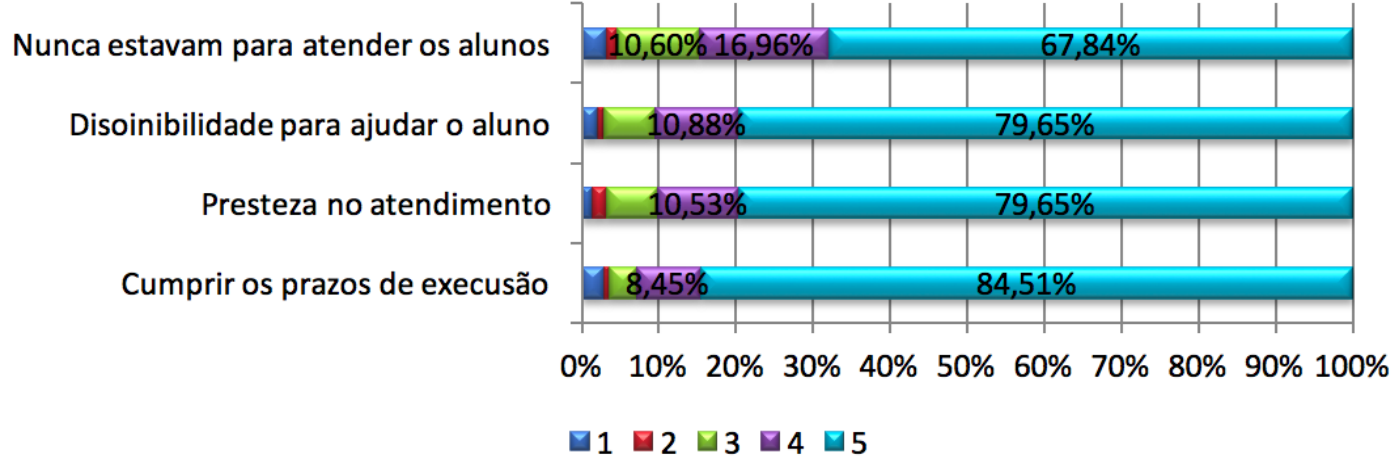

Para os usuários dos CFC, a empresa cumpriu os prazos de execução prometidos e, dessa forma, avaliaram as empresas de forma bastante satisfatória com nota 4,71, o que significa rendimento de mais $95 \%$. Dos clientes que participaram da pesquisa, $92,76 \%$ conferiram nota 4 ou 5 , sendo que $84,51 \%$ marcaram nota máxima para o CFC.

Presteza no atendimento ao cliente obteve nota 4,67, com rendimento acima dos $95 \%$ e, do total dos clientes que responderam a pesquisa, 90,49\% atribuíram nota 4 ou 5 a este quesito, sendo que 
Id on Line Revista Multidisciplinar e de Psicoloqia

Id on Line Revista Multidisciplinar e de Psicologia

79,93\% assinalou a nota máxima ao item em questão, revelando que acreditam que o CFC presta serviço de qualidade.

De acordo com os respondentes, os instrutores e funcionários sempre estavam dispostos a ajudar, impondo nota de 4,67. Quanto a estes nunca estarem ocupados para esclarecer suas dúvidas, a média foi de 4,43 sendo esta a menor nota no aspecto sensibilidade, mas sendo ainda muito boa, apresentando rendimento acima dos $85 \%$.

\section{Segurança}

Esta seção busca demonstrar a opinião dos participantes no que tange ao atendimento por parte dos funcionários da empresa, especialmente sobre a segurança que transmitem nas transações e credibilidade que inspiram. As respostas estão distribuídas na Tabela 4 e ilustradas na Figura 5 a seguir.

TABELA 4: Resultados acerca da Sensibilidade. Para um N absoluto de 288 questionários. PetrolinaPE, 2016.

\begin{tabular}{c|c|c|c|c|c|c|c}
\hline SEGURANÇA & $\mathbf{1}$ & $\mathbf{2}$ & $\mathbf{3}$ & $\mathbf{4}$ & $\mathbf{5}$ & $\begin{array}{c}\text { Média } \\
\text { Ponderada }\end{array}$ & $\begin{array}{c}\text { Desvio } \\
\text { Padrão }\end{array}$ \\
\hline $\begin{array}{c}\text { Inspira confiança } \\
\text { (N=283) }\end{array}$ & $1,77 \%$ & $1,06 \%$ & $5,3 \%$ & $14,49 \%$ & $77,39 \%$ & $\mathbf{4 , 6 5}$ & 0,33 \\
\hline $\begin{array}{c}\text { Segurança nas } \\
\text { transações (N=284) }\end{array}$ & $1,41 \%$ & $0,35 \%$ & $8,8 \%$ & $11,97 \%$ & $77,46 \%$ & $\mathbf{4 , 6 4}$ & 0,32 \\
\hline Educação (N=284) & $1,41 \%$ & $1,41 \%$ & $3,52 \%$ & $7,39 \%$ & $86,27 \%$ & $\mathbf{4 , 7 6}$ & 0,37 \\
\hline $\begin{array}{c}\text { Conhecimento } \\
\text { (N=283) }\end{array}$ & $1,06 \%$ & $0,35 \%$ & $4,95 \%$ & $8,13 \%$ & $85,51 \%$ & $\mathbf{4 , 7 7}$ & 0,37 \\
\hline
\end{tabular}

Fonte: Dados da Pesquisa de campo

Figura 5 - Dimensão Segurança em parâmetros

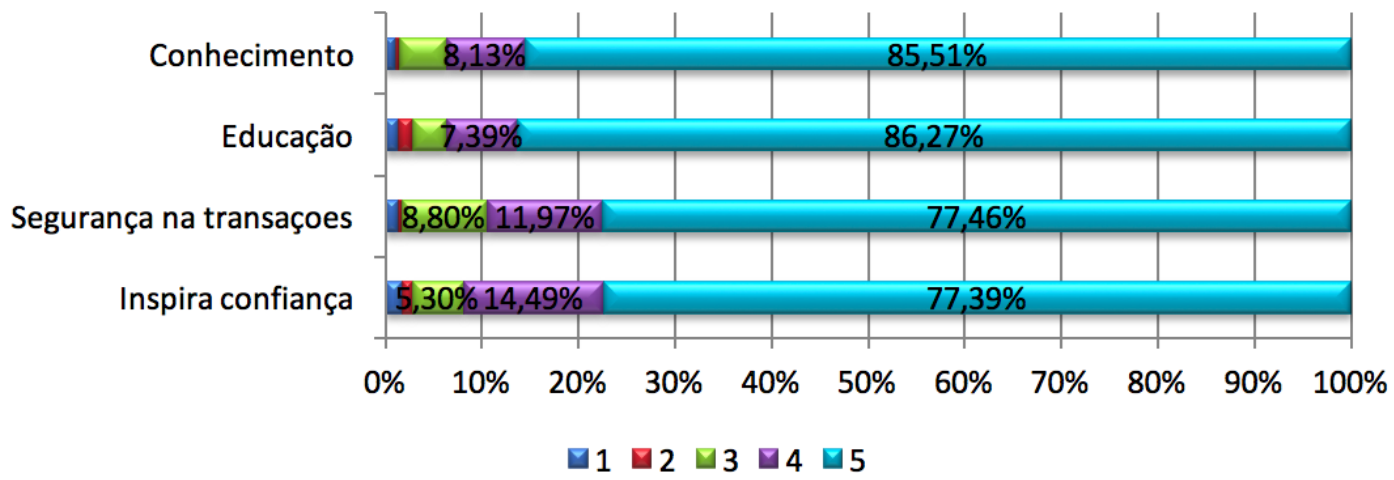

Para os clientes, os instrutores e funcionários do $\mathrm{CFC}$ onde realizaram o processo de aprendizagem inspiravam confiança, sendo que $91,82 \%$ da clientela atribuíram nota 4 ou 5 e 77,11\% 
conferiram a nota máxima. Dessa forma, os CFC obtiveram uma nota média de 4,63, com rendimento acima de $95 \%$.

As transações realizadas entre o $\mathrm{CFC}$ e a clientela inspiraram segurança de tal forma que $89,43 \%$ assinalaram nota 4 ou 5, sendo que 77,46\% marcaram a nota máxima. Mesmo assim, a nota média desse item $(4,64)$ foi a mais baixa para este eixo.

De acordo com os participantes, os instrutores e funcionários sempre foram educados e possuíam conhecimento sobre o assunto ministrado, representando nos aspectos melhores avaliados no tocante à segurança, já que estes itens foram os que receberam as maiores notas, tendo respectivamente 4,76 e 4,77 , ou seja, rendimento de mais de $95 \%$.

\section{Empatia}

O último item avaliado pela Servqual busca compreender como a empresa se coloca no lugar de seus clientes, sobretudo na atenção individual e atendimento das necessidades dos alunos. O resultado desta dimensão segue detalhado na Tabela 5 e diagramado na Figura 6 a seguir.

TABELA 5: Resultados acerca da Empatia. Para um N absoluto de 288 questionários. Petrolina-PE, 2016.

\begin{tabular}{c|c|c|c|c|c|c|c}
\hline EMPATIA & $\mathbf{1}$ & $\mathbf{2}$ & $\mathbf{3}$ & $\mathbf{4}$ & $\mathbf{5}$ & $\begin{array}{c}\text { Média } \\
\text { Ponderada }\end{array}$ & $\begin{array}{c}\text { Desvio } \\
\text { Padrão }\end{array}$ \\
\hline $\begin{array}{c}\text { Atenção } \\
\text { Individual } \\
\text { (N=284) }\end{array}$ & $3,52 \%$ & $0,35 \%$ & $8,45 \%$ & $12,32 \%$ & $75,35 \%$ & $\mathbf{4 , 5 6}$ & 0,31 \\
\hline $\begin{array}{c}\text { Horários } \\
\text { Flexíveis (N=285) }\end{array}$ & $3,16 \%$ & $1,4 \%$ & $7,37 \%$ & $15,09 \%$ & $72,98 \%$ & $\mathbf{4 , 5 3}$ & 0,30 \\
\hline $\begin{array}{c}\text { Atenção Pessoal } \\
\text { aos outros alunos } \\
\text { (N=284) }\end{array}$ & $4,23 \%$ & $1,76 \%$ & $8,80 \%$ & $15,14 \%$ & $70,07 \%$ & $\mathbf{4 , 4 5}$ & 0,28 \\
\hline $\begin{array}{c}\text { Prioridade no } \\
\text { Melhor Serviço } \\
\text { (N=284) }\end{array}$ & $2,11 \%$ & $0,70 \%$ & $8,80 \%$ & $10,56 \%$ & $77,82 \%$ & $\mathbf{4 , 6 1}$ & 0,33 \\
\hline $\begin{array}{c}\text { Atende às } \\
\text { Necessidades dos } \\
\text { Alunos (N=284) }\end{array}$ & $2,82 \%$ & $0,70 \%$ & $7,04 \%$ & $14,08 \%$ & $75,35 \%$ & $\mathbf{4 , 5 8}$ & 0,31 \\
\hline Flung Das Pes & & & &
\end{tabular}

Fonte: Dados da Pesquisa de campo 
Id on Line Revista Multidisciplinar e de Psicoloqia Id on Line Revista Multidisciplinar e de Psicologia

Figura 6 - Dimensão Empatia em parâmetros

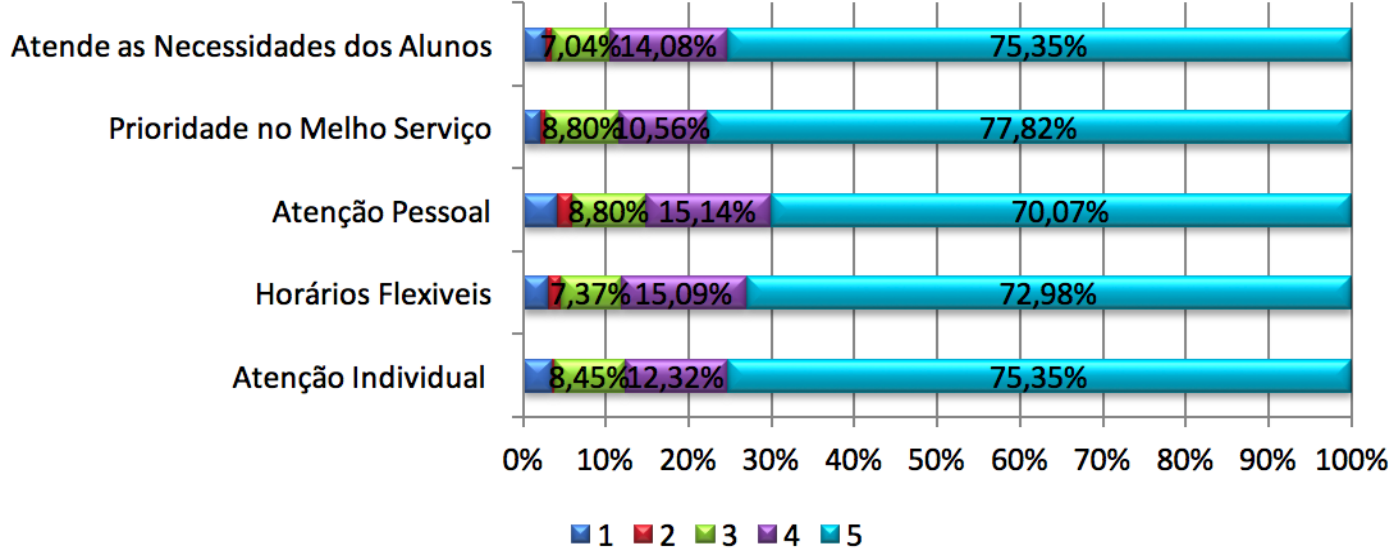

Para os clientes, o CFC - através de seus funcionários e instrutores, prestaram atenção individual aos alunos, sendo que $87,67 \%$ conferiram nota 4 ou 5 a este quesito e, destes, $75,35 \%$ atribuíram nota máxima. Os candidatos também sentiam que havia atenção pessoal aos outros alunos e por isso $85,21 \%$ atribuíram nota 4 ou 5, sendo que 70,07\% atribuíram nota máxima.

A dimensão encontra-se em acordo com Assmann, Moyano e Angnes (2013), no tocante a relação entre o sucesso e a capacidade da empresa em atender necessidades e expectativas da clientela.

Ainda para os participantes, as autoescolas apresentavam horários flexíveis para atender aos alunos e, assim, 72,98\% da amostra avaliou com nota máxima este ponto, o que gerou nota média de 4,53. Os estudantes conferiram também nota média de 4,61 ao item prioridade em prestar o melhor serviço, sendo que $88,38 \%$ da amostra deu nota 4 ou 5 , a melhor avaliação para a empatia da empresa. A grande maioria acreditava que a autoescola atendia às necessidades dos alunos, com média de 4,58.

Quanto aos achados por meio da escala Servqual, estes evidenciam que o serviço prestado, na visão dos clientes, está em linha com outros estudos (BESSANI, 2009; ASSMAN, MOYANO, ANGNES, 2013).

\section{Semáforo das Considerações Finais}

Esta investigação de caráter eminentemente quantitativo com uma amostra de 288 entrevistados, estudou o universo circunscrito pela VIII CIRETRAN/PE no tocante aos CFCs. O objetivo foi, a partir do ponto de vista do condutor da primeira habilitação, investigar por meio de dimensões a qualidade dos CFCs no interior do estado.

Com o escopo da investigação atendido, os achados revelam que todos os itens receberam avaliação acima da média, sendo medidos como serviços de boa qualidade. Aqueles referentes à tangibilidade que tiveram maiores médias foram material didático, que consideraram atualizados, e 
Id on Line Revista Multidisciplinar e de Psicologia

Id on Line Revista Multidisciplinar e de Psicologia

aparência dos funcionários. Entretanto, dois quesitos tiveram as menores médias, sendo eles equipamentos modernos e instalações físicas.

No que se refere ao eixo confiabilidade, a melhor avaliação deu-se para o comprometimento na execução dos serviços. Mesmo assim, os itens com menores médias foram interesse na solução de problemas e execução do serviço sem erros, que merece um olhar por parte daqueles que gerem as empresas. Deve-se considerar que este aspectos envolve o treinamento e capacitação dos funcionários para que desenvolvam suas tarefas de forma mais eficiente. Onde, de acordo com Soares, Queiroz e Caffé Filho (2016), o entrosamento de colaboradores e gestão quanto ao desenvolvimento de pessoal é necessário para o trabalho amplo onde se busque melhor participação, com implantações de programas contínuos de qualificação para o desenvolvimento de pessoal.

A dimensão sensibilidade apresentou como menor média os ítens presteza no atendimento e disponibilidade em esclarecer dúvidas dos alunos. É válido destacar o processo ensino-aprendizagem precisa estar junto do educando, auxiliando-o na construção do conhecimento, o que pode interferir diretamente na aprovação nos exames do DETRAN e na atuação como condutor.

$\mathrm{Na}$ questão segurança, obtiveram menores médias a segurança nas transações e o comportamento dos instrutores e demais funcionários quanto a inspirarem confiança. Vale destacar que esta tem forte ligação com a dimensão anterior, já que quando a disponibilidade encontra-se comprometida, os funcionários podem não inspirar confiança.

A atenção pessoal, aquela que o CFC dispensa a cada cliente e referente à dimensão empatia, também teve menor média dentre as demais. $\mathrm{O}$ sucesso de uma organização está relacionado à sua capacidade de atender necessidades e expectativas da clientela, devendo os serviços ser desenvolvidos de forma a criar valor para satisfazê-los.

Diante das elevadas taxas de acidentes e da importância atribuída com o passar dos anos aos CFCs, a qualidade que os CFCs imprimem em seus serviços transcende o simples aspecto de manutenção de mercado no tocante a concorrência. Este serviço merece ser reverenciado e estimado sob o olhar mais crítico do poder público na tentativa de trabalhar políticas públicas dirigidas aos trabalhos desenvolvidos dentro dos Centros de Formação de Condutores, principalmente, no quesito da primeira habilitação.

Dessa forma, a contar dos achados, se sugere que os serviços devem estar em contínua avaliação e melhoria; onde, para avançarem, os CFCs devem dar destaque às instalações físicas, modernização de equipamentos e capacitação dos funcionários de modo a obterem uma interface mais apropriada com o seu alunado, aqui visto como condutor de primeira habilitação.

Diante do nível de satisfação e do alto índice de acidentes fica as dúvidas: em que momento a política de habilitação está falhando? Seria possível associar os acidentes ao formação deficitária do condutor por meio das CFCs? Seria possível desenvolver políticas de penalização associadas aos índices de acidentes provocados por condutores formados por cada CFCs? Sendo assim, sugere-se 
Id on Line Revista Multidisciplinar e de Psicoloqia

Id on Line Revista Multidisciplinar e de Psicologia

como pesquisas futuras o desenvolvimento de trabalhos que busquem a desenvolver parâmetros a responder as provocações acima.

\section{Referências}

ABREU, A. M. M.; LIMA, J. M. B.; LIMA, J. M. B. O impacto do álcool na mortalidade em acidentes de trânsito: uma questão de saúde pública. Esc. Anna Nery [online]. 2006, vol.10, n.1, pp.87-94.

ALVES, C.A., GOMES, J.O. Contribuições da psicologia do trânsito: considerações sobre educação para o trânsito e formação profissional. Rev. Científica da FAMINAS. 10(3): 61-74, 2014.

ASSMANN, T., MOYANO, C.A.M., ANGNES, D.L. A satisfação dos clientes de uma empresa de Formação de Condutores (CFC). In: RIBEIRA, V.B. et al. Estudos acadêmicos em administração, contábeis, economia e relações internacionais. Santa Cruz do Sul: EDUNISC, 2013. P. 21-30.

BESSANI, R. Percepção versus desempenho: um estudo dos serviços ao cliente do Centro de Formação de Condutores VIP. Universidade do Vale do Itajaí [Trabalho de Conclusão de Curso]. 2009. 94p.

BISSOLI, C. C. M.; MAZETTO, M. D. C.; CARLOS, C. M.G. Fatores que interferem na direção veicular de condutores categoria E. UNAR. Revista Científica do Centro Universitário de Araras "Dr. Edmundo Ulson", v. 6, p. 1, 2012.

CONTRAN - Conselho Nacional de Transito. Conf. Art. 143 do CTB e Res. 168. 2004. Disponível em:www.denatran.gov.br/download/resolucoes/resolucao_contran_168.pdf. Acessado em: 8.jan.2016

Resolução no 358. de 13 de agosto de 2010. 2010.

CRISTO, F.; ALCHIERI, J. C. Validade preditiva de instrumentos psicológicos usados na avaliação psicológica de condutores. Psicologia: Teoria e Pesquisa (UnB. Impresso), v. 26, p. 695-706, 2010.

DENATRAN - Departamento Nacional de Trânsito. Resolução nº 168/169 do Contran. 2004.

Resolução $\mathbf{n}^{\mathbf{0}} \quad \mathbf{3 5 8} / \mathbf{1 0}$ do Contran. 2010. Disponível em:

www.denatran.gov.br/download/.../resolucao_contran_358_10_ret.pdf. Acessado em: 08.jun.2016

Lei $\mathbf{n}^{\mathbf{0}}$ 9.503, de 23 de setembro de 1997. 1997

Pacto Nacional pela Redução de Acidentes. 2011. Disponível em: http://www.denatran.gov.br/decada_transito.htm. Acesso em: 08.jun.2016

Campanha de trânsito permanente. 2012. Disponível em: http://www.denatran.gov.br/ultimas/20120921_lancamento.htm. Acesso em: 16.mai. 2015

DETRAN-PE. Estatísticas Atuais. Secretaria das Cidades de Pernambuco. 2010. Disponível em:http://www.detran.pe.gov.br/index.php?option=com_content\&view=article\&id=36\&Itemid=72. Acesso 19 abr. 2016.

IBGE. Instituto Brasileiro de Geografia. Projeção da população do Brasil e das Unidades da Federação. 2016. Disponível em: <http://www.ibge.gov.br/apps/populacao/projecao〉. Acesso em: 22 abr. 2016

LOVELOCK, C.; WRIGHT, L. Serviços: Marketing e Gestão. São Paulo: Saraiva, 2004. 
Id on Line Revista Multidisciplinar e de Psicoloqia

Id on Line Revista Multidisciplinar e de Psicologia

MASCHIO, L. Posto Avançado DETRAN de Colombo-PR: proposta para suprir a demanda de candidatos a prestar exame prático de direção veicular de primeira habilitação categoria B. PósGraduação em Gestão Pública, Setor de Ciências Sociais e Aplicadas, Universidade Federal do Paraná. Curitiba. 2011

MOYSÉS, S. J. Determinação sociocultural dos Acidentes de transporte Terrestre (ATT). Ciência e Saúde Coletiva. 17(9):2237-2245, 2012.

NAKANO, T. C.; SAMPAIO, M. H. L.; SILVA, A. B. Atenção e inteligência em candidatos à primeira carteira nacional. Boletim de Psicologia, v. 61, p. 63-78, 2011.

OPAS - Organização Pan-Americana da Saúde. Segurança de pedestres: Manual de segurança viária para gestores e profissionais da área. Brasília, DF : OPAS, 2013.

PEREIRA, I.G.; NEVES, F.S. Comportamento de risco: uma revisão bibliográfica sobre as causas de acidentes de trânsito nos últimos 10 anos. Rev. Cereus. 5(2):73-89, 2013.

PINHEIRO, A. L. F. B.; PILEGGI, G. C. F.; GAUBEUR, I. Fortes, R. M. Educação para o trânsito e responsabilidade social. Anais do XXXIV COBENGE. Passo Fundo: Ed. Universidade de Passo Fundo, Setembro de 2006. P. 9.189-202.

RAAD, A. J.; CARDOZO, A. M.; NASCIMENTO, M. A.; ALVES, G. L. Ansiedade no processo para obtenção da Carteira Nacional de Habilitação. Psic (São Paulo. Impresso), v. 9, p. 135-144, 2008.

RODRIGUES, D. A.; JAYO, M. Modernização administrativa em contexto subnacional: estudo de caso do Detran-SP. Cadernos Gestão Pública e Cidadania, v. 21, n. 68, p. 63-85, 2016.

SANTOS, J. A. História do transporte rodoviário. Revista Ibero-Americana de Estratégia, v. 1, n. 1, p. 27-32, 2002.

SARTORI, F. V.; LAROCCA, A. P. C.; ALMQVIST, R. O simulador de direção veicular e o processo de habilitação do condutor no Brasil: estudos de validação e proposta de melhoria. In: Anais do XXVIII Congresso ANPET 2014, 2014, Curitiba/PR. XXVIII Congresso ANPET 2014, 2014.

SILVA, A. M. K.; TRENHAGO, J. Mulheres com medo de dirigir: um olhar além das aparências. Psicologia.pt - $\mathrm{O}$ portal dos psicólogos. 2015. Disponível em: www.psicologia.pt/artigos/textos/TL0371.pdf. Acessado em: 04.jun.2016

SILVA, E.J. As dimensões da qualidade no segmento de centros de formação de condutores de Curitiba/PR. Universidade Federal do Rio Grande do Sul [Dissertação de Mestrado]. 2005. 92p.

SOBRINHO, E. A. Adolescência e Trânsito. IGT na Rede, v. 7, p. 02-17, 2010.

SOARES, V. B. dos S.; QUEIROZ, L. A. B.; CAFFE FILHO, H. P. A Importância do fator motivacional no trabalho: uma abordagem crítica. Id on Line Revista de Psicologia, 10(29): 23-36, 2016.

STEFANO, N. M., CASAROTTO FILHO, N. Avaliação da qualidade dos serviços por meio da Escala Servqual de Parasuraman et al. Estudos do ISCA. 4(6):1-10, 2013.

TRINKS, L. A., BORBA, M. F. Motivação e satisfação dos colaboradores da empresa Centro de Formação de Condutores Real LTDA. In: RIBEIRA, V.B. et al. Estudos acadêmicos em administração, contábeis, economia e relações internacionais. Santa Cruz do Sul: EDUNISC, 2013. 
VIAS SEGURAS. Fatores ligados aos veículos. 2016. Disponível em: http://www.viasseguras.com/os_acidentes/causas_de_acidentes/fator_veiculo. Acessado em: 8.jun.2016

VIEIRA, T. A. Competência Policial militar para atuar no trânsito: do policiamento à fiscalização de trânsito. Revista Ordem Pública - ACORS, n. 1, Texto 2, 2008

WAISELFISZ, J. J. Mapa da Violência 2012: os novos padrões da violência homicida no Brasil. São Paulo: Instituto Sangari, 2012.

WAISELFISZ, J.J. Mapa da Violência 2013: Acidentes de Trânsito e Motocicletas no Brasil. São Paulo: Instituto Sangari, 2013.

WHO - WORLD HEALTH ORGANIZATION. World report on road traffic injury prevention. Geneva. 2004. Disponível em: http://whqlibdoc.who.int/publications/2004/9241562609.pdf Acessado em 07.abril.2016.

ZEITHAML, V. A.; BITNER, M. J. Marketing de serviços: a empresa com foco no cliente. 2.ed. Porto Alegre: Bookman, 2003.

\section{Como citar este artigo (Formato ABNT):}

SILVA, G.L.; CASSUNDÉ JÚNIOR, N.F.; COSTA, S.P. Dimensões de Qualidade dos CFCs sob a Percepção dos Condutores de Primeira Habilitação. Id on Line Revista de Psicologia, Julho de 2016, vol.10, n.30, Supl 2. p. 149-168. ISSN 1981-1179.

Recebido: 11/06/2016

Aceito:16/06/2016 